\title{
Evacuation Departure Timing during Hurricane Matthew
}

\author{
ERIKA O. PHAM \\ Hazards and Vulnerability Research Institute, Department of Geography, University of South Carolina, Columbia, \\ South Carolina

\section{CHRISTOPHER T. EMRICH} \\ National Center for Integrated Coastal Research, School of Public Administration, University of Central Florida, \\ Orlando, Florida \\ ZHENLONG LI \\ Hazards and Vulnerability Research Institute, Department of Geography, University of South Carolina, Columbia, \\ South Carolina \\ JAMIE MITCHEM \\ Institute for Environmental and Spatial Analysis, University of North Georgia, Oakwood, Georgia \\ SUSAN L. CUTTER \\ Hazards and Vulnerability Research Institute, Department of Geography, University of South Carolina, Columbia, \\ South Carolina
}

(Manuscript received 15 February 2019, in final form 26 November 2019)

\begin{abstract}
This study investigates evacuation behaviors associated with Hurricane Matthew in October of 2016. It assesses factors influencing evacuation decisions and evacuation departure times for Florida, Georgia, and South Carolina from an online survey of respondents. Approximately $62 \%$ of the Florida sample, $77 \%$ of the Georgia sample, and $67 \%$ of the South Carolina sample evacuated. Logistic regression analysis of the departures in the overall time period identified variability in evacuation timing, primarily dependent on prior experience, receipt of an evacuation order, and talking with others about the evacuation order. However, using four logistic regressions to analyze differences in departure times by day shows that the only significant variable across the three main days of evacuation was our proxy variable for evacuation-order times. Depending on the day, other variables of interest include number of household vehicles, previous hurricane experience, and receipt of an evacuation order. Descriptive results show that many variables are considered in the decision to evacuate, but results from subsequent analyses, and respondents' comments about their experiences, highlight that evacuation orders are the primary triggering variable for when residents left.
\end{abstract}

\section{Introduction}

Hurricane Matthew (28 September-9 October 2016) was the last storm of the 2016 hurricane season for the southeastern coastal regions of the United States. Matthew became a tropical storm on 28 September, west-northwest of Barbados; it developed into a category-5 storm in the Caribbean Sea, making it the

Corresponding author: Erika O. Pham, epham@email.sc.edu strongest Atlantic Ocean storm of the 2016 season and also the deadliest (Stewart 2016). The storm's U.S. path severely affected the eastern coasts of Florida, Georgia, and South and North Carolina while heavy rain and wind brought flooding and wind damage in the interior parts of these states. Matthew tracked northward, parallel to the coastline for over $560 \mathrm{mi}(900 \mathrm{~km})$, with a shifting track and uncertain landfall locations. It ultimately weakened and made U.S. landfall as a category-1 hurricane near McClellanville, South Carolina 
(Stewart 2016), near where Hurricane Hugo made landfall in 1989, and continued moving parallel to the coastline for another 300 miles $(480 \mathrm{~km})$ or more. Approximately 1-4 days before the hurricane's projected landfall, the governors of Florida, Georgia, and South Carolina ordered evacuations for multiple counties along the coasts.

There are numerous variables involved in a household's evacuation decision-making process, with many identified in previous research. The ongoing coverage of Matthew's continually shifting track meant individual and household decisions to evacuate or remain were also being continuously updated, thereby affecting evacuation departure times. Thus, Hurricane Matthew presents an interesting case for analyzing the spatiotemporal stages and variables affecting the hurricane evacuation decision-making process.

This paper examines spatial/temporal differences, their interactions with other factors, and their influences on evacuation behaviors along the eastern coasts of Florida, Georgia, and South Carolina in response to Hurricane Matthew. Specifically, the paper addresses household-level variables that might explain such variations in the amount of time between warning issuance and the initiation of the evacuation response by local residents.

\section{Background}

There is extensive literature on hurricane evacuation behaviors dating back decades. In Baker's (1991) analyses of hurricane evacuation behaviors and variables of survey respondents for 12 hurricanes in a variety of geographic locations within the southeastern United States, he found that, among numerous other factors, the differences in evacuation behaviors were generally explained by the individual's perception of risk (held beliefs). Later research confirmed the importance of storm-specific physical factors in an individual's decision to evacuate or remain (e.g., Dow and Cutter 1998; Whitehead et al. 2000; Smith and McCarty 2009; Stein et al. 2010; Bowser and Cutter 2015). Much of the literature confirms the significance of recommendations of protective actions from public officials (e.g., mandatory/voluntary evacuation orders) in prompting evacuations (Dow and Cutter 1998; Whitehead et al. 2000; Smith and McCarty 2009; Stein et al. 2010; Bowser and Cutter 2015; Huang et al. 2016). Huang et al.'s (2016) statistical meta-analysis of over 49 actual and hypothetical evacuation studies since Baker's (1991) analyses enhanced the current understanding that local officials are indeed vital and influential sources of information in evacuation decision-making at the household level, and that an official order is consistently positively correlated with evacuations.

A number of other variables are consistent in terms of their significance on evacuation outcomes, such as private vehicle ownership for traveling to a variety of sheltering options, the type of housing of a resident, or pet ownership. However, bearing weak, inconsistent, or no direct significance on evacuation outcomes are some demographic factors, like age, gender, or race; previous hurricane experience; exposure to previous false alarms; and previous participation in shadow evacuations (Baker 1991; Dow and Cutter 1998; Whitehead et al. 2000; Whitehead 2003; Arlikatti et al. 2006; Smith and McCarty 2009; Lindell et al. 2011; Bowser and Cutter 2015; Huang et al. 2016). It is important to note, however, that simply because these variables have been shown to have weak or no effects on evacuation according to past research, it does not mean that they will be insignificant variables in new case studies.

Information-seeking, knowledge-confirmation processes and the subsequent translation into action or nonaction are also important to consider when studying evacuation behaviors. An evolving facet of evacuation processes is information seeking and "milling" (Mileti and Peek 2000; Eiser et al. 2012); that is, more information on the hurricane is both disseminated and sought out, with confirmation sought from family and friends. However, sometimes the interpretation of the information is faulty, and an individual may not take the most appropriate actions, even though forecasts, watches, and warnings are provided well in advance of landfall (Broad et al. 2007; Pasch et al. 2004; National Weather Service 2006). In other cases, an individual's social situation, such as the perceived dependability, density, or diversity of their social networks (Collins et al. 2017; Collins et al. 2018), or psychosocial factors such as self-sufficiency or strong social networks (Wong-Parodi and Feygina 2018), may frame the decision to evacuate or remain.

While much of the hurricane evacuation literature addresses the variables that influence the decisionmaking process and the subsequent choice to evacuate or remain, there seems to be less certainty in terms of the behavioral drivers that influence the variability in hurricane evacuation departure times. Studies on evacuation timing with a technological or modeling focus often, for example, assume full compliance with warnings, no processes of shadow evacuation, various vehicle occupancies (Lindell and Prater 2007), or simultaneous evacuations (Sbayti and Mahmassani 2006). Others focus on infrastructural or network problems with little regard to the behavioral aspects that play a significant role in the departure timing and evacuation preferences of an individual or household (Pel et al. 2010). 
The common assumptions in many evacuation timing studies often run counter to actual occurrences, such as the evacuation during Hurricane Floyd in 1999: There was intense evacuation traffic congestion as a result of one-half of the evacuees departing in the same 6-h window, about one-quarter of the evacuees taking more than one vehicle, and most traveling farther than was necessary to ensure safety (Dow and Cutter 2002). These findings support Mileti and Sorensen's (2019) "protective action initiation time"- the lag between when warnings are issued and when residents begin to take protective actions such as evacuation. The lag time exists because of the need to take preparatory actions, such as making accommodations elsewhere, compounded by, for instance, the presence of pets, children, elderly family members, or those with physical ailments, but some of it is also a function of residents seeking confirmatory information on the nature of the threat (milling), clarity of the warnings, the time of day at which the warning is received, or length of residency in the area (Mileti and Peek 2000; Lindell and Prater 2007; Dixit et al. 2012; Mileti and Sorensen 2019). However, the delay does not occur for all residents because some may choose to leave prior to an official mandated order for their area or because of their interpretation of storm threats or expectation of complicating issues in travel, such as traffic congestion.

There are exceptions that have investigated physical and/or demographic variables contributing to household decisions to evacuate, and decisions on when to leave [e.g., Lindell et al. 2005 (Hurricane Lili); Fu et al. 2007 (Hurricanes Floyd and Andrew); Koshute 2013 (Hurricanes Hugo, Andrew, Opal, Fran, Ivan, and Jeanne); Hasan et al. 2013 (Hurricane Ivan); Sarwar et al. 2016 (Hurricane Ivan)]. These studies have looked at different combinations of chosen variables, such as time of day, evacuation notice/type, storm characteristics (e.g., wind speed, time to landfall, movement speed, and predicted surge height), evacuation characteristics (e.g., destination, duration between decision and evacuation, travel time, and vehicle ownership), household/housing characteristics (e.g., housing type and location, distance to water bodies, children, and pets), and demographics (e.g., marital status, age, income, education, and race/ethnicity). A number of these variables have been found to be either inconsistently significant or insignificant altogether, with the exception of time of day, evacuation notice type (mandatory/voluntary), and some of the storm-specific characteristics. As Hurricane Matthew presents a new case with potentially different circumstances, it is therefore valuable to examine whether household characteristics partially explain differences in evacuation, not only with respect to compliance, but also evacuation preferences and departure timing.

We do not attempt to fully model evacuation behaviors, but we build on the existing hurricane evacuation literature by considering some variables discussed in this review, known to influence overall evacuation outcomes and decision-making. We also include some of the variables typically found to be inconsistent in their contributions to evacuation, but thought to affect behaviors in some way. The variables of most interest in assessing the evacuation response include: approximate time of either mandatory or voluntary evacuation order (using the respondent's state as a proxy variable); prior hurricane experience; perceived receipt of an evacuation order; number of information sources used in the decisionmaking; number of different information channels used; milling behavior (number of different consultations used, e.g., neighbor, friends); perceived residence within an evacuation zone; perceived residence within a Federal Emergency Management Agency (FEMA)-designated flood zone; number of occupants in the household; number of pets in the household; number of automobiles owned; and household income.

\section{Method}

\section{a. Study area}

Our study area is the Atlantic coast of Florida, Georgia, and South Carolina, based on the extent of watches and warnings issued as Hurricane Matthew advanced northward. In our study area, the first hurricane watch and warning issued by the National Hurricane Center occurred in Florida on Tuesday 4 October, and Wednesday 5 October, respectively [a table of all of the times that watches and warnings were issued or updated can be accessed in Stewart (2016)]. The governors of the three states declared states of emergencies with evacuations (voluntary or mandatory) ordered by state or local officials along the coasts. While there were some county differences in evacuation-order times, a general pattern emerged: of the three states, South Carolina coastal residents received the first notice for a mandatory evacuation on Tuesday 4 October, to begin Wednesday 5 October (Table 1). Florida coastal residents began receiving orders on Wednesday 5 October, with some counties starting with voluntary orders, and escalating to mandatory orders by Thursday 6 October. Georgia coastal residents began receiving orders on the morning of Thursday 6 October.

\section{b. Survey method}

Over 45000 postcard invitations were mailed to a random coastal resident sample in Florida, Georgia, and 
TABLE 1. Evacuation recommendations/orders and times for Florida (FL), Georgia (GA), and South Carolina (SC) coastal counties. See Fig. 1 for a map of the counties. Sources may have to be accessed via an Internet archive or a supplementary source.

\begin{tabular}{|c|c|c|c|c|}
\hline State & County & Locations/zones & Type & Date ordered (notes) \\
\hline FL & Brevard $^{\mathrm{a}, \mathrm{b}}$ & Barrier islands & Mandatory & 5 Oct 2016 (to begin 1500 LT 5 Oct) \\
\hline FL & Duval $^{\mathrm{a}, \mathrm{c}}$ & $\mathrm{A}, \mathrm{B}$, and $\mathrm{C}$ & Mandatory & 5 Oct 2016 (began as voluntary) \\
\hline FL & Flagler $^{\mathrm{a}}$ & $\mathrm{A}$ and $\mathrm{B}$ & Mandatory & $\begin{array}{l}5 \text { Oct } 2016 \text { (began as voluntary on } \\
5 \text { Oct; mandatory by } 6 \text { Oct) }\end{array}$ \\
\hline FL & Indian River ${ }^{\mathrm{b}}$ & $\begin{array}{l}\text { Barrier islands, mobile homes, and } \\
\text { low-lying areas }\end{array}$ & Mandatory & $\begin{array}{l}6 \text { Oct } 2016 \text { (began as voluntary } 5 \text { Oct; } \\
\text { mandatory by } 0800 \text { LT } 6 \text { Oct) }\end{array}$ \\
\hline FL & Martin $^{\mathrm{b}}$ & $\begin{array}{l}\text { Sewall's Point, Hutchinson Island, } \\
\text { Jupiter Island, and mobile homes }\end{array}$ & Mandatory & 5 Oct 2016 (to have begun) \\
\hline FL & Nassau $^{\mathrm{b}}$ & $\mathrm{A}, \mathrm{C}$, and $\mathrm{F}$ & Mandatory & 6 Oct 2016 (to begin at $0600 \mathrm{LT}$ ) \\
\hline FL & Palm Beach ${ }^{\mathrm{b}}$ & $\mathrm{A}$ and $\mathrm{B}$ & Mandatory & 5 Oct 2016 (to begin 5 Oct) \\
\hline FL & St Johns ${ }^{\mathrm{b}}$ & $\mathrm{A}, \mathrm{B}$, and $\mathrm{F}$ & Mandatory & $\begin{array}{l}6 \text { Oct } 2016 \text { (began as voluntary } 5 \text { Oct; } \\
\text { mandatory by } 0600 \text { LT } 6 \text { Oct) }\end{array}$ \\
\hline FL & St Lucie ${ }^{a, b}$ & Barrier islands and low-lying areas & Mandatory & $\begin{array}{l}6 \text { Oct } 2016 \text { (began as voluntary } 5 \text { Oct; } \\
\text { mandatory by } 6 \text { Oct) }\end{array}$ \\
\hline FL & St Lucie ${ }^{a}$ & East of U.S. Rte. 1 & Voluntary & 5 Oct 2016 (to have begun) \\
\hline FL & Volusia $^{\mathrm{b}}$ & $\begin{array}{l}\text { Beachside, low-lying areas, } \\
\text { recreational vehicles, and } \\
\text { mobile homes }\end{array}$ & Mandatory & $\begin{array}{l}6 \text { Oct } 2016 \text { (began as voluntary } 5 \text { Oct; } \\
\text { mandatory by } 0600 \text { LT } 6 \text { Oct) }\end{array}$ \\
\hline GA & $\begin{array}{l}\text { Bryan, Camden, Chatham, } \\
\text { Glynn, Liberty, and McIntosh }\end{array}$ & East of Interstate Hwy 95 (I-95) & Mandatory & 6 Oct 2016 (morning) \\
\hline GA & Above counties ${ }^{\mathrm{d}}$ & West of I-95 & Voluntary & 6 Oct 2016 (morning) \\
\hline $\mathrm{SC}$ & Beaufort, Colleton, and Jasper ${ }^{\mathrm{e}}$ & A & Mandatory & $\begin{array}{l}\text { Announced } 4 \text { Oct } 2016 \text { (to begin } \\
1500 \text { LT } 5 \text { Oct) }\end{array}$ \\
\hline $\mathrm{SC}$ & Berkeley $^{\mathrm{e}}$ & $B$ and $G$ & Mandatory & $\begin{array}{l}\text { Announced } 4 \text { Oct } 2016 \text { (to begin } \\
1500 \text { LT } 5 \text { Oct) }\end{array}$ \\
\hline $\mathrm{SC}$ & Charleston $^{\mathrm{e}}$ & $\mathrm{A}, \mathrm{B}$, and $\mathrm{C}$ & Mandatory & $\begin{array}{l}\text { Announced } 4 \text { Oct } 2016 \text { (to begin } \\
1500 \text { LT } 5 \text { Oct) }\end{array}$ \\
\hline $\mathrm{SC}$ & Colleton and Jasper ${ }^{\mathrm{g}}$ & B & Mandatory & $\begin{array}{l}6 \text { Oct } 2016 \text { ("effective immediately" } \\
\text { on } 6 \text { Oct) }\end{array}$ \\
\hline $\mathrm{SC}$ & Dorchester $^{\mathrm{e}}$ & $\mathrm{B}, \mathrm{D}, \mathrm{E}$, and $\mathrm{F}$ & Mandatory & $\begin{array}{l}\text { Announced } 4 \text { Oct } 2016 \text { (to begin } \\
1500 \text { LT } 5 \text { Oct) }\end{array}$ \\
\hline SC & Georgetown and Horry ${ }^{\mathrm{f}}$ & A & Mandatory & 6 Oct 2016 (to begin $1200 \mathrm{LT}$ ) \\
\hline
\end{tabular}

${ }^{\text {a } h t t p s: / / q a . f l g o v . c o m / 2016 / 10 / 05 / 47411 / . ~}$

${ }^{\mathrm{b}}$ https://web.archive.org/web/20161111062238/https://www.flgov.com/2016/10/05/gov-scott-issues-updates-on-hurricane-matthew-preparednessefforts-as-storm-approaches-florida-3/.

${ }^{\mathrm{c}}$ https://www.wokv.com/news/local/county-county-evacuations/EZPRnwk5crlzzmXQRVIsjJ/.

${ }^{\mathrm{d}}$ https://www.ajc.com/blog/politics/georgia-orders-evacuation-residents-six-coastal-counties-ahead-hurricane-matthew/Mua9aSGtAFb99j3kjqju4J/.

${ }^{\mathrm{e}} \mathrm{https} / /$ web.archive.org/web/20161220090450/http://scemd.org/component/content/article/11-home-page/news/240-matthew-news-release-4.

${ }_{\mathrm{f}}^{\mathrm{f}}$ https://web.archive.org/web/20161230085832/http://scemd.org/component/content/article/11-home-page/news/245-matthew-news-release-8.

${ }^{\mathrm{g}}$ https://web.archive.org/web/20180330131242/http://www.scemd.org/component/content/article/11-home-page/news/247-matthewnews-release-9.

South Carolina coastal counties ordered to evacuate from Matthew (Fig. 1). North Carolina was omitted from the study area because of storm track, strength, and lack of resources for additional surveys. Infogroup, a data analytics services firm, provided the addresses for our sampling frame of households in potential storm-surge zones along the coast. The postcards provided a link to an online survey platform made available by SurveyMonkey.

The survey instrument consisted of a total of 49 fixedformat and open-ended questions. The first question was required and asked the respondent to enter the unique code provided on their postcard, which allowed us to match the mailing address to their responses. Aside from this question, the respondent could skip any questions they did not want to answer. There were 46 questions on topics like prior experience, risk area awareness, information sources, influences on behavior, and demographic questions. However, depending on certain responses, questions were automatically skipped. For instance, if someone answered that they did not evacuate, the survey skipped a block of questions asking them about evacuation (e.g., where did they go, when they left, how much they spent, or how many vehicles they took), and immediately led them to a question about what factors influenced their decision to remain. The evacuee group could answer at most 


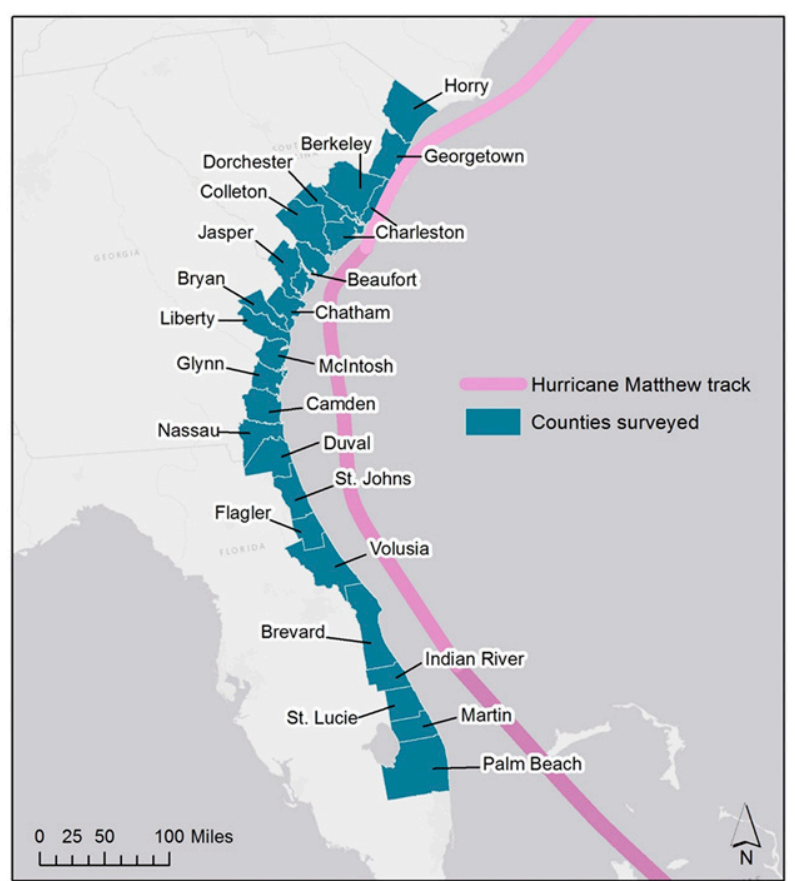

FIG. 1. Florida, Georgia, and South Carolina coastal counties that received the hurricane evacuation survey. Our random selection was based on the spatial extent of hurricane evacuation zones and also included some residents living just outside the zones to potentially capture differences in behavior on the basis of zonal/nonzonal occupancy.

48 questions, while the nonevacuee group could answer at most 35. One question provided the respondent an opportunity to share their experiences and concerns about the evacuation process or state/local management of the event (free response). Another question provided the respondent an opportunity to enter into a drawing for a 16-GByte digital tablet (\$399 manufacturer's suggested retail price). Respondents were told the survey would take no more than $15 \mathrm{~min}$, and the average survey taker took $12 \mathrm{~min}$.

The Internet-based delivery was designed to speed up the deployment, response, and assessment of the responses. However, this survey method contributed to the low response rate (less than $2 \%$ ), because Internetbased surveys consistently provide low numbers of respondents (Leece et al. 2004; Fan and Yan 2010; Guo et al. 2016), and on top of this, overall survey response rates appear to be decreasing over time (Cull et al. 2005; Johnson and Wislar 2012). Additionally, lack of Internet access or inability to use Internet-based services would impact the response rate. A number of reasons, such as hurricane damage, no Internet service, rurality, age, or income, could skew the responses toward privileged populations. Further, the survey was accessible from November to mid-December 2016, and influences such as the national elections and holiday season during the
TABLE 2. Response rates and confidence.

\begin{tabular}{lcccc}
\hline \hline & & & & South \\
& Overall & Florida & Georgia & Carolina \\
\hline Postcards delivered & 48347 & 18240 & 10278 & 19829 \\
Responses received & 735 & 238 & 168 & 329 \\
Response rate (\%) & 1.52 & 1.30 & 1.63 & 1.66 \\
Responses used & 697 & 225 & 159 & 313 \\
$\begin{array}{c}\text { Total population in } \\
\quad \text { study counties }\end{array}$ & 3814112 & 2375637 & 465135 & 973340 \\
$\begin{array}{c}\text { Confidence intervals of } \\
\quad \text { responses received }\end{array}$ & \pm 3.61 & \pm 6.35 & \pm 7.56 & \pm 5.40 \\
\hline
\end{tabular}

survey deployment and response time frame may have contributed to the low response rate.

The total sample size of $n=697$ breaks down as follows across the study area: Florida $n=225$, Georgia $n=159$, and South Carolina $n=313$. Table 2 provides an overview of the total responses received and the response rates, with corresponding confidence intervals. Those who supplied a departure time sum to an $n=465$ out of a total evacuation group of $n=472$ (in other words, several respondents evacuated but did not provide us with a time of departure). Some responses were unusable as they were duplicates; a possible explanation for some duplicates is that a respondent could have exited the website (intentionally or unintentionally) partway through the survey, returned, and took the survey again. Other responses were omitted because of their large numbers of skipped questions (e.g., answering only three questions, or not answering whether they evacuated, which was central to the analysis). Returned survey data were coded, standardized, and consolidated for use in the analyses.

\section{c. Sample representativeness}

Table 3 shows the demographic breakdown of our sample and the 24 study area counties, using data from the 2015 five-year American Community Survey (ACS). While most of these values are significantly different, we only selected two of the variables shown below for use in the analysis (among other variables), household income and number of vehicles available at the household. Further, the values from the ACS are at county-level scale, whereas our survey respondents live in coastal areas (i.e., evacuation zones), and this may result in some of the discrepancies shown. We emphasize that the sample in this study is not as representative of the general population as we would like, but provides a useful case study of hurricane evacuees.

\section{Descriptive results}

The survey found $68 \%$ of the 697 survey respondents evacuated, with the following state breakdown: 
TABLE 3. Sample representativeness.

\begin{tabular}{lcc}
\hline \multicolumn{1}{c}{ Demographic variables } & $\begin{array}{c}\text { 2015 ACS } \\
\text { (county level) }\end{array}$ & $\begin{array}{c}\text { Survey } \\
\text { (coastal areas) }\end{array}$ \\
\hline Male & $48.6 \%$ & $49.5 \%$ \\
Female & $51.4 \%$ & $50.5 \%$ \\
Median age $^{\mathrm{a}}$ & 41.3 & 63 \\
White $_{\text {Black or African American }}$ & $73.3 \%$ & $91.2 \%$ \\
At least one vehicle available $^{\text {Median household income }}{ }^{\mathrm{b}}$ & $19.8 \%$ & $4.6 \%$ \\
Med $^{2}$ & $\$ 3.5 \%$ & $98.3 \%$ \\
\hline
\end{tabular}

${ }^{a}$ Average median age was calculated from median ages provided by the ACS, whereas median age was used for the survey.

${ }^{b}$ Average household income was used for the survey, because income ranges were provided to respondents; midpoints of each range were calculated, and those midpoints were used to calculate the average.

$62 \%$ of the Florida sample (total $n=225$ ), $77 \%$ of the Georgia sample (total $n=159$ ), and $67 \%$ of the South Carolina sample (total $n=313$ ) evacuated. More than $70 \%$ of the respondents said they received an evacuation order but this ranged from a low of $70 \%$ in Florida, $72 \%$ in South Carolina, to $91 \%$ in Georgia. Interestingly, although $89 \%, 100 \%$, and $84 \%$ of Florida, Georgia, and South Carolina respondents actually live in any evacuation zone, respectively, only $68 \%, 65 \%$, and $71 \%$ answered that their residence is located within one.

Among the evacuees, the survey asked what factors influenced the decision to evacuate (Fig. 2). For Florida, Georgia, and South Carolina, the hurricane's track was the primary motivator $(79 \%, 75 \%, 71 \%$, respectively), with marginal to no significant differences between the groups. The hurricane's strength was an additional motivator for Florida and Georgia (79\%,
$73 \%$ ), but a secondary motivator for South Carolina $(57 \%)$. The difference may be due to the shift in classification from "major hurricane" to simply "hurricane" along the Georgia coast. However, it is unclear whether the interpretations of "hurricane strength" were in regard to flood/surge potential, wind potential, or both. A third motivating factor in evacuating was receiving a mandatory evacuation order $(56 \%, 66 \%$, and $56 \%$, respectively).

\section{Departure times}

Given our primary interest in evacuation departure timing, the 472 respondents who said they evacuated were asked the day and time of departure and were provided with 35 possible time intervals, or time steps, to choose from. 464 of these respondents provided us with a departure time. Admittedly, memory decay presents a concern, particularly two months after the event. We attempted to reduce these effects by providing in the survey broad time steps that correspond to early morning, late morning, early afternoon, late afternoon, evening, and late night. The 35 possible choices consist of the 5-day span between Tuesday 4 October and Saturday 8 October, with seven time segments [0000-0600, 0600-0900, 0900-1200, 1200-1500, 15001800, 1800-2100, and 2100-0000 local time (LT)].

For South Carolina, the initial peak of evacuee departures essentially falls between 0000 and 1800 Wednesday 5 October, which was the day South Carolina Governor Haley mandated most evacuations to begin (Fig. 3). Voluntary and mandatory evacuation orders for coastal Florida residents came on 5 and 6 October, and the departures for these days

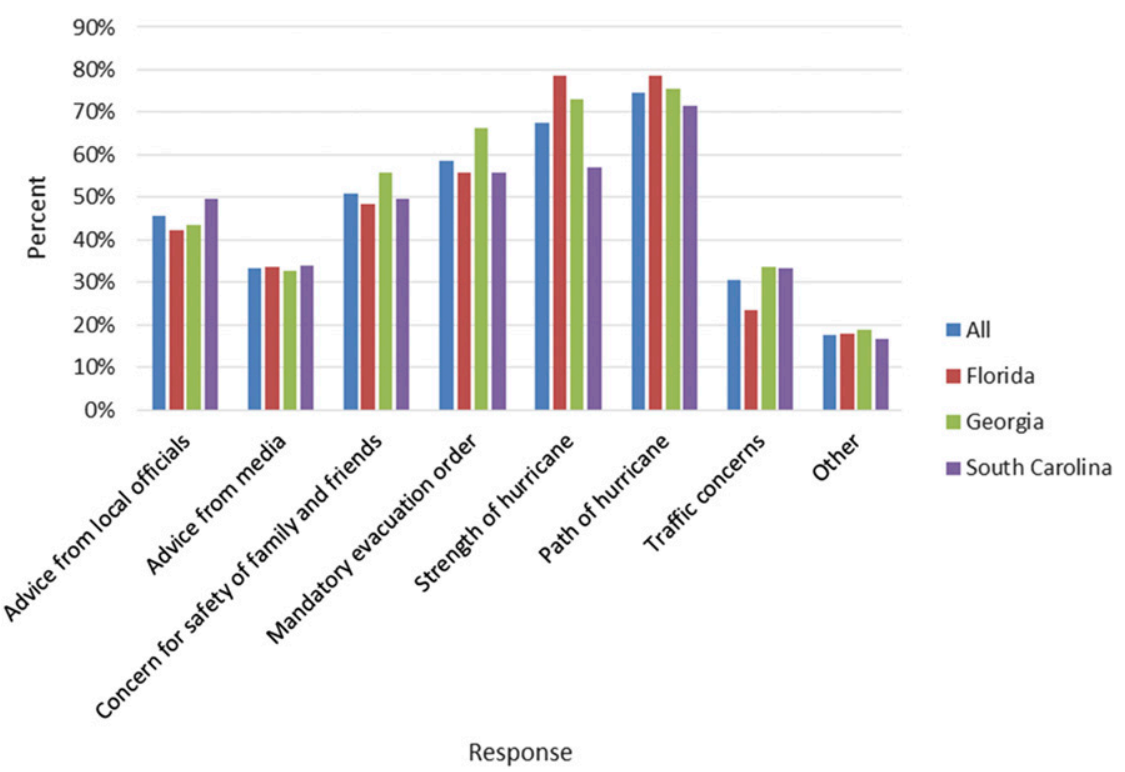

FIG. 2. Factors influencing the decision to evacuate. 


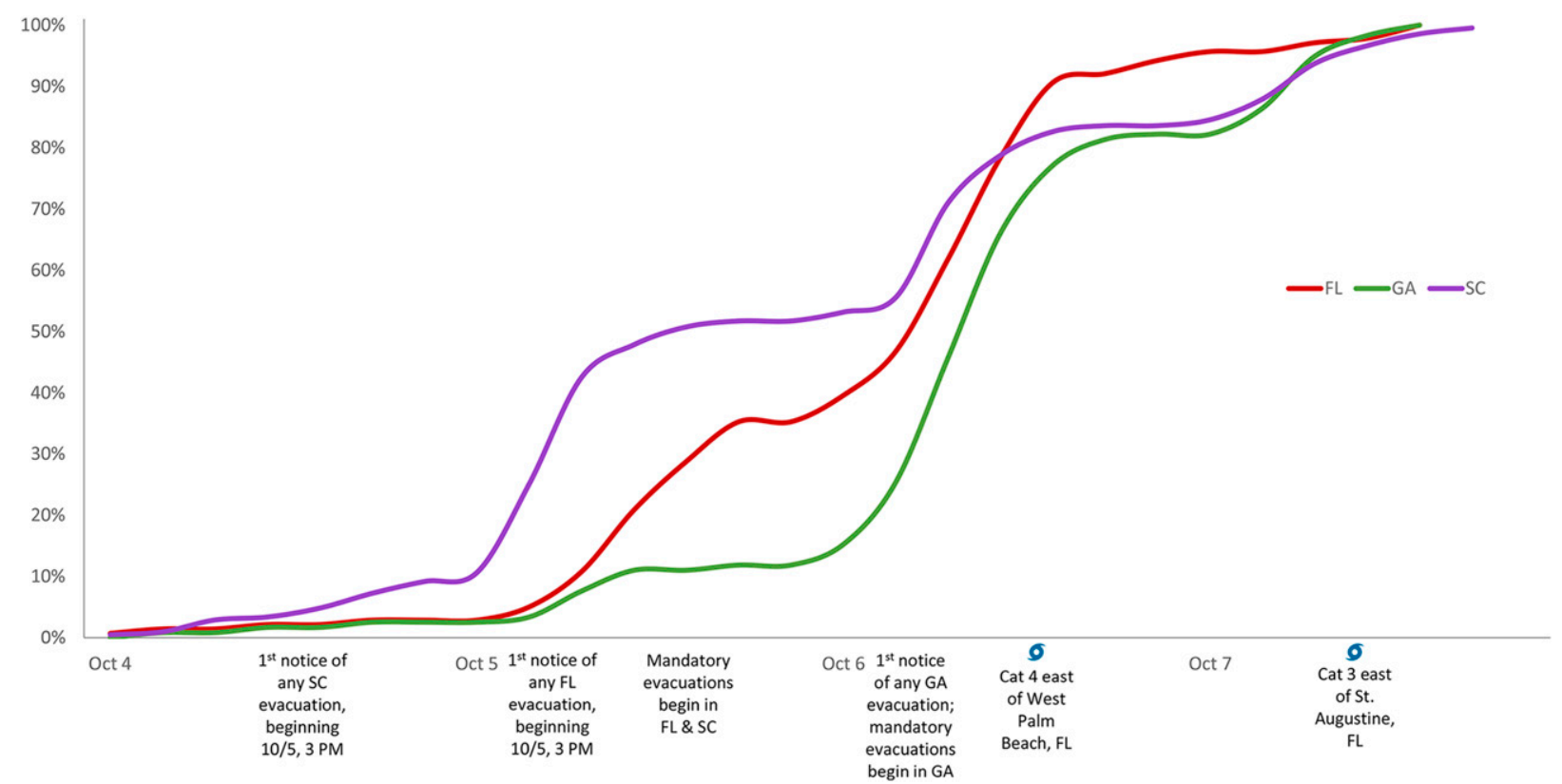

FIG. 3. Percent of departures from Tuesday 4 Oct between 0000 and 0600 local time to Friday 7 Oct between 1800 and 2100 local time. The graph represents only those evacuees who supplied a departure time (total $n=464$; Florida $n=139$; Georgia $n=118$; South Carolina $n=207$ ).

are also visible in the plot, primarily between 0600 and 2100 Thursday 6 October. A more gradual, initial peak can be seen on Wednesday 5 October. The mandatory evacuation order for Georgia was given Thursday 6 October, showing a significant evacuation response, followed by additional departures on Friday 7 October between 0900 and 1200. While a number of variables influenced a household's decision to evacuate (see Fig. 2), and some residents do evacuate earlier (before an evacuation order), the sample data here highlight that an authoritative evacuation order may be the primary triggering variable in the timing of departures. Although the respondent-cited influences in evacuation were primarily the track and strength of the hurricane, the more significant responses in the plot for each state in Fig. 3 are associated with the evacuation orders given by those states. This finding emphasizes the necessity of timely action in order for successful evacuation procedures to take place and, in the event of another hurricane and evacuation, could promote increased compliance.

\section{Evacuation and departure time analysis}

Using logistic regression, we analyzed differences in behavioral responses and their correlates for the 4-day period, and break down the analyses by day to assess which variables significantly contribute to departure timing. In aggregating the departure time responses by day, we understand that we are losing finer temporal variability within a day, but we also aim to ameliorate the effects of memory decay pertaining to the general time a respondent left (e.g., morning, afternoon, evening). Additionally, we briefly discuss some open-ended responses, as statistical results cannot capture the complete evacuation experience or reveal factors contributing to evacuation beliefs and behaviors that we may not have considered. Therefore it is also important to consider other factors like perceptions, past and current experiences, and social factors when analyzing human behavior.

\section{a. Logistic regression analysis}

To examine differences in evacuation behavior and departure times as a function of household-level characteristics five logistic regression models were specified-one for the overall time period, and the other four representing each day of evacuation-and estimated using SAS/STAT software. While there are multiple ways to deal with missing values (Little and Rubin 2002; Kang 2013), they were only dealt with using the default method of listwise deletion, the default procedure.

The first regression models the probability of a household evacuating over the entire study period. From the questions asked in the survey, and based on existing literature, we pared down the variables to the ones thought to be of importance to the analysis; there were 12 variables (Table 4) selected for inclusion in the first regression (called ALLDAYS) because of their potential to change the probability of a household evacuation. For the first regression (ALLDAYS), 
TABLE 4. Variables selected for inclusion in the regressions (ALLDAYS included all 12, and DAY1-4 excluded WHOSCORE, HOWSCORE, and TELLSCORE, for a total of 9).

\begin{tabular}{|c|c|c|c|}
\hline Variable & Description & Response & Category \\
\hline \multirow[t]{3}{*}{ STATE } & \multirow[t]{3}{*}{ Dummy variable: proxy for time of evacuation order } & $\mathrm{SC}$ & 1 \\
\hline & & FL & 2 \\
\hline & & GA & 3 \\
\hline \multirow[t]{2}{*}{ PREEXP } & \multirow{2}{*}{$\begin{array}{l}\text { Dummy variable: whether the respondent has experienced a hurricane prior } \\
\text { to Matthew }\end{array}$} & No & 0 \\
\hline & & Yes & 1 \\
\hline \multirow[t]{2}{*}{ EVACORDER } & \multirow{2}{*}{$\begin{array}{l}\text { Dummy variable: whether the respondent thinks they received an order to } \\
\text { evacuate from Matthew }\end{array}$} & No & 0 \\
\hline & & Yes & 1 \\
\hline WHOSCORE & $\begin{array}{l}\text { Sum of the no. of types of evacuation-information sources the respondent } \\
\text { used (police, media, governor, coworker, employer, etc.) }\end{array}$ & & $0-9$ \\
\hline HOWSCORE & $\begin{array}{l}\text { Sum of the no. of types of evacuation-information modes the respondent used } \\
\text { (social media, radio, television, newspaper, face-to-face communication, etc.) }\end{array}$ & & $0-9$ \\
\hline TELLSCORE & $\begin{array}{l}\text { Sum of the no. of types of people the respondent told about the evacuation order } \\
\text { (neighbor, friend, coworker, employer, etc.) }\end{array}$ & & $0-6$ \\
\hline \multirow[t]{3}{*}{ EVACZONE } & \multirow[t]{3}{*}{ Dummy variable: whether the respondent thinks they live in an evacuation zone } & No & 0 \\
\hline & & Yes & 1 \\
\hline & & Do not know & 2 \\
\hline \multirow[t]{3}{*}{ FEMAZONE } & \multirow{3}{*}{$\begin{array}{l}\text { Dummy variable: whether the respondent thinks they live in a FEMA-designated } \\
\text { flood zone }\end{array}$} & No & 0 \\
\hline & & Yes & 1 \\
\hline & & Do not know & 2 \\
\hline NLIVHH & No. of occupants in household & Free response & \\
\hline NAUTOHH & No. of automobiles owned by household & Free response & \\
\hline NPETS & No. of pets in household & Free response & \\
\hline \multirow[t]{5}{*}{ HHINC2015 } & Household income in 2015 as ordinal variable (five levels) & Less than $\$ 22,000$ & 1 \\
\hline & & $\$ 22,001-\$ 43,999$ & 2 \\
\hline & & $\$ 44,000-\$ 65,999$ & 3 \\
\hline & & $\$ 66,000-\$ 87,999$ & 4 \\
\hline & & $\$ 88,000$ or more & 5 \\
\hline
\end{tabular}

136 observations were deleted because of missing values and 561 of the 697 observations were used. A correlation matrix of our selected variables is provided in Table 5 .

The other four regressions model the relationship between evacuation and multiple variables for each of the four ${ }^{1}$ days of evacuation. In this way, we can begin to understand which variables significantly affected evacuation timing during Hurricane Matthew, for this sample. The data used were stratified by day (the regressions are labeled DAY1-DAY4), and variables were selected on the basis of existing literature. Of the questions asked in the survey, there were nine regressors (see Table 4) selected for inclusion in the model because of their potential to change the probability of a household evacuation in time interval $t$. The milling variables were removed from the variable list in these four regressions because they increased the number of listwise-deleted observations due to missing values, and we did not think

\footnotetext{
${ }^{1}$ Because only one respondent needed to evacuate on Saturday 8 October because of flooding associated with Matthew, the maximum likelihood estimate does not exist for the fifth day's regression model and is thus invalid.
}

their removal would significantly change the meaning of the analysis. Of the 465 evacuee observations with departure times, 383 were used in each of the four regressions. Forward selection was used to identify the effects contributing to evacuation. The significance level selected for entry into the model was 0.10 , to not only capture significant variables at $\alpha=0.05$, but also to identify variables of interest that could benefit from further study. We want to emphasize that we selected a nonstandard significance level because of the exploratory, rather than definitive, nature of the study.

\section{b. Results and discussion for overall evacuation response}

The results of the first model (Table 6) provide some insight to why a household evacuated during the entire study period. Over the duration of the evacuation for all three states, an evacuation response from this sample depends on prior experience with hurricanes $(p<0.01)$, receipt of an evacuation order $(p<0.01)$, and how many others the respondent told about the evacuation $(p<0.01)$. Whether they believed they live in an evacuation zone $(p=0.07)$, the number of pets in the household $(p=0.06)$, and household income $(p=0.06)$ are variables of interest with $p$ values just above $\alpha=0.05$. 


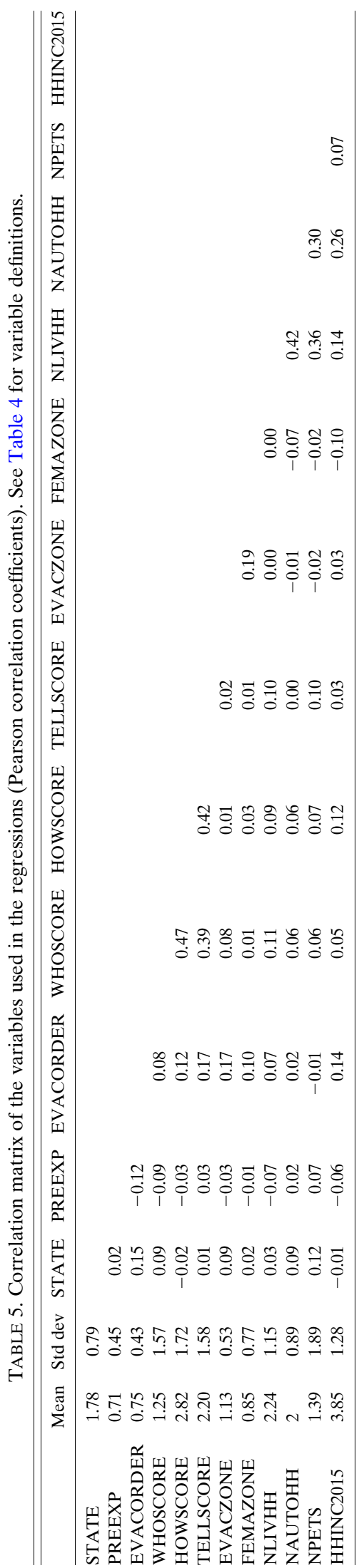

TABLE 6. Analysis of effects and significance. See Table 4 for variable definitions. Variables that are significant at $\alpha=0.05$ are indicated by an asterisk. Here, DF is degrees of freedom.

\begin{tabular}{lccc}
\hline \multicolumn{1}{c}{ Effect } & DF & Wald chi-square & $p$ value \\
\hline STATE & 1 & 0.03 & 0.87 \\
PREEXP* & 1 & 10.31 & 0.00 \\
EVACORDER* & 1 & 37.94 & 0.00 \\
WHOSCORE & 1 & 0.13 & 0.72 \\
HOWSCORE & 1 & 0.08 & 0.78 \\
TELLSCORE* & 1 & 7.49 & 0.00 \\
EVACZONE & 2 & 5.32 & 0.07 \\
FEMAZONE & 2 & 2.55 & 0.28 \\
NLIVHH & 1 & 0.08 & 0.78 \\
NAUTOHH & 1 & 0.38 & 0.54 \\
NPETS & 1 & 3.68 & 0.06 \\
HHINC2015 & 1 & 3.50 & 0.06 \\
\hline
\end{tabular}

The results show there is strong evidence that the odds of evacuating for those without prior hurricane experience are about twice the odds of evacuating for those with prior experience (Table 7), which contradicts the nonsignificant effect found in Baker (1991) and Huang et al. (2016). The importance of evacuation orders agrees with prior studies (e.g., Baker 1991; Huang et al. 2016) since the odds of evacuating for those who thought they received an evacuation order are about 4.8 times higher than those who thought they did not receive one. Similarly, for a one unit increase in the number of subjects the respondent told about the evacuation order, the odds of evacuating increased by a factor of about 1.2. This relationship between milling and evacuation has not been addressed in prior hurricane evacuation studies with the exception of the recent Lindell et al. (2019) flood evacuation study.

Some prior research shows evidence that pet ownership decreases the chance of evacuation for that household (Whitehead 2003; Edmonds and Cutter 2008; Bowser and Cutter 2015). With a hard cutoff at $\alpha=0.05$, our results contradict such findings; however, we argue that it remains a variable of interest in this case study ( $p=0.06$ ), and that we find marginal evidence of how pet ownership may constrain evacuation. In contrast, household income plays an inconsistent or nonsignificant role in evacuation behavior (Huang et al. 2016). In our study, income is also a variable of interest. However, one must acknowledge that income is often confounded with other variables such as risk area (Baker 1991) and exercise caution with interpretation. Believing one's residence is located in an evacuation zone has been shown to be influential but is insignificant here, although it is still a variable of interest $(p=0.07)$ and we find it reasonable to conclude that we found marginal evidence for risk area awareness affecting evacuation. To clarify, 
TABLE 7. Odds ratio estimates for evacuation, and Wald confidence intervals for the odds ratio estimates. See Table 4 for variable definitions. Variables that are significant at $\alpha=0.05$ are indicated by an asterisk.

\begin{tabular}{|c|c|c|c|}
\hline \multirow[t]{2}{*}{ Odds ratio } & \multirow{2}{*}{$\begin{array}{c}\text { Estimate } \\
0.98\end{array}$} & \multicolumn{2}{|c|}{$\begin{array}{l}90 \% \\
\text { confidence } \\
\text { limits }\end{array}$} \\
\hline & & 0.78 & 1.22 \\
\hline PREEXP no vs yes* & 2.23 & 1.48 & 3.35 \\
\hline EVACORDER no vs yes* & 0.21 & 0.14 & 0.32 \\
\hline WHOSCORE & 0.97 & 0.86 & 1.1 \\
\hline HOWSCORE & 0.98 & 0.87 & 1.1 \\
\hline TELLSCORE* & 1.23 & 1.08 & 1.38 \\
\hline EVACZONE no vs yes & 0.43 & 0.21 & 0.89 \\
\hline EVACZONE no vs do not know & 0.34 & 0.16 & 0.73 \\
\hline EVACZONE yes vs do not know & 0.79 & 0.51 & 1.22 \\
\hline FEMAZONE no vs yes & 0.71 & 0.48 & 1.06 \\
\hline FEMAZONE no vs do not know & 0.72 & 0.47 & 1.11 \\
\hline FEMAZONE yes vs do not know & 1.01 & 0.64 & 1.60 \\
\hline NLIVHH & 0.97 & 0.83 & 1.14 \\
\hline NAUTOHH & 0.92 & 0.74 & 1.14 \\
\hline NPETS & 0.90 & 0.82 & 0.99 \\
\hline HHINC2015 & 1.17 & 1.02 & 1.35 \\
\hline
\end{tabular}

any inaccuracies in the respondents' knowledge of their risk area (see section 4, descriptive results) do not invalidate these results, as the results do not necessarily rely on the actual knowledge of living in an evacuation zone, but rather the belief or perception that one does/does not live in a zone. In other words, regardless of whether they are actually located in a zone, if they believe that they do or do not, it may have an impact on their evacuation behavior. In this case, surprisingly, it appears to not have had a strong significant effect.

There are inconsistencies in previous research results on the influence of past hurricane experience on evacuation response. Based on our results, there is strong evidence that the lack of prior hurricane experience increased the chance of an evacuation, compared to those who had past hurricane experience. There are many potential explanations for this phenomenon. For example, more experienced individuals or households feel better prepared to weather a hurricane, or that past hurricanes were not severe enough to warrant an evacuation. Another reason could be that past hurricanes were regarded as inconvenient experiences (Demuth et al. 2016) compounded by factors such as traffic concerns or not being able to return home promptly (e.g., Dash and Morrow 2000). Open-ended responses from our survey offer additional insights. For example, some respondents not only complained about the delay in returning home, but also were incredibly frustrated with the lack of communication about the delay, with some stating that these would be factors in future evacuation decisions. A sampling of such responses is in Table 8.

\section{c. Results and discussion for analyses by day}

The model results for each day allow us to assess the potential reasons for the departure timing of evacuations (Table 9). The results for the first day (DAY1-Tuesday 4 October) show that only the STATE variable was found to significantly affect evacuation, with number of automobiles (NAUTOHH) as a variable of interest. The regression results for both the second and third days (DAY2-Wednesday 5 October; DAY3 - Thursday 6 October) reveal very strong evidence that the chance a household evacuates changes only with the state/time of evacuation order, holding all other variables constant. On day 4 of the evacuation-Friday 7 October-Hurricane Matthew was just off the east coast of Florida as a category-4 hurricane (downgraded to a 3 on the same day). The results for the fourth day (DAY4) reveal strong evidence that the chance a household evacuates changes by state (STATE) and previous evacuation experience (PREEXP), while the receipt of an evacuation order is only what we consider a variable of interest. No other variables met the 0.10 significance criteria for entry into the models.

While Table 9 shows that STATE significantly affected evacuation on DAY1, Table 10 shows that this effect disappears with the addition of the variable for number of automobiles (we acknowledge that this is a drawback of the selection method). Effectively, there are no significant variables on DAY1. Because the first evacuation orders were announced on day 1 (Tuesday 4 October) in South Carolina (to begin officially on day 2), people were still making the necessary preparations for evacuation. In other words, in terms of official evacuation procedures, relatively little had happened on day 1 for residents except for receiving a "heads up" to prepare for evacuating the following days. Some respondents said that they left on day 1 , but not many. The number of automobiles does not have a significant effect at $\alpha=0.05$, but it may be worth noting that there was marginal evidence that more cars in a household decreased the chance of evacuation on day 1 . This could be reflective of a household deciding what vehicle(s) to take, deciding whether to split a household into multiple departures, or a larger household with more assets to consider in the evacuation process.

In contrast, for the second day (Wednesday 5 October), there is strong evidence that the time of evacuation order was a key indicator because the odds of evacuation for South Carolina respondents were about 7 times those of Georgia respondents, and the odds of evacuation for Florida respondents were about 4.7 times those of 
TABLE 8. Selected quotations from respondents reflecting frustrations that may impact future evacuation decisions.

\begin{abstract}
Georgia
"After hurricane Floyd did not [want] to get in the massive traffic jam."

"The city of Brunswick had a unique experience with re-entry. The city announced that everyone was allowed to return with no limitations/exceptions, but the state troopers blocked the on/off ramps and refused re-entry to anyone, including residents. For an entire day, they re-directed people attempting to re-enter Brunswick around and around a loop. The troopers were not helpful in providing information, and even prohibited our local news reporters (who stayed to keep locals informed about the situation) from entering the city. This experience will definitely negatively factor into any future decision to evacuate."

"Would probably leave for a stronger hurricane or more direct hit. Neighbors had trouble returning home, which discourages some from evacuating."

"One major concern of evacuating was the difficulty of returning home. We stayed and would have had to wait several days to return home to check on our house."
\end{abstract}

"Governor overplayed evacuation requirements."

Florida

"I would evacuate as a last choice. Being on a peninsula, you stand a good chance of being stuck on the road. Also, the hurricanes change direction and unless it's a cat 5, I'd stay put."

"Our gated community is .4 mile from the Atlantic. A limb hit our deck railing causing light damage otherwise we were totally untouched. Next time I'll stay."

"I will be better [prepared] the next time. [And] leave early or stay on the island like most of my family this was not a good experience just like Floyd, or move out of this state."

\title{
South Carolina
}

"They needed to let the residents back in sooner than they did. This will [affect] my decision to stay or go for the next Hurricane."

"We'd consider evacuation for future anticipated hurricane strikes to the Lowcountry, as we'll never forget experiencing Hurricane Hugo at a friend's new home in Goose Creek. However, the state government's never-failing interminable delay in allowing property owners to return home and secure their structure(s) and belongings prohibits us in good conscience from seriously considering actually making an evacuation unless there's a $90+\%$ probability of absolute total destruction in the southern Dorchester County area."

"The Governor was totally hysterical and raised too much public alarm for a minor hurricane. I will not evacuate next time unless I am convinced by my own evaluation that the hurricane is truly dangerous. I wasted over $\$ 900$ in travel and hotel expenses for a totally unnecessary evacuation. The evacuation order should have been restricted strictly to coastal areas/islands. Too many people were evacuated causing chaos and too many people on the roads."

"Due to return process delay of 3 days, not sure we will evacuate next time."

Georgia respondents. On day 3 of evacuation, we found that the odds of evacuation for Georgia respondents were almost 5 times the odds of evacuation for South Carolina respondents (1/0.206), whereas there was no significant difference in evacuation between Georgia and Florida respondents. We frame these results in the context of evacuation order or announcement times-in general, 4 October for South Carolina, 5 October for Florida, and 6 October for Georgia.

For the fourth day, there is strong evidence that the odds of evacuating for those with prior hurricane experience were almost 2.5 times the odds of evacuating for those without prior hurricane experience (1/0.404), which contrasts the results for the overall period (see Table 7). The odds of evacuation for Georgia respondents were about 6 times those for people living in Florida on day 4 (1/0.161). Evacuations ordered for coastal Georgia began on Thursday (day 3), and most of the Florida residents who could evacuate or who wanted to evacuate may have done so by this time, resulting in this difference. We find marginal evidence that the receipt of an evacuation order affected evacuation on DAY4, whereby those who did not receive an order may have been more likely to evacuate. We infer that potentially most of those who did receive an order had already evacuated, so the only people who could still evacuate would be those who did not receive an evacuation order. Overall, we see that there are changes in the evacuation patterns of each state over time. We essentially find that the chance a household evacuates changes with the

TABLE 9. Variables meeting the criteria to enter the models via forward selection. See Table 4 for variable definitions.

\begin{tabular}{lccccccc}
\hline \hline Model day no.: & 1 & 1 & 2 & 3 & 4 & 4 & 4 \\
\hline Effect entered & STATE & NAUTOHH & STATE & STATE & STATE & PREEXP & EVACORDER \\
DF & 2 & 1 & 2 & 1 & 1 & 2 & 1 \\
No. in & 1 & 2 & 31.58 & 41.86 & 11.60 & 2 & 7.46 \\
Score chi-square & 7.07 & 3.48 & 0 & 0 & 0 & 0 & 3 \\
$p$ value & 0.03 & 0.06 & & & & 0.07 \\
\hline
\end{tabular}


TABLE 10. Analysis of maximum likelihood estimates-DAY1-DAY4. See Table 4 for variable definitions. Variables that are significant at $\alpha=0.05$ are indicated by an asterisk. Here, "Exp (est)" refers to the exponentiated parameter estimates.

\begin{tabular}{|c|c|c|c|c|c|c|c|c|}
\hline & Parameter & & DF & Estimate & Std error & Wald chi-square & $p$ value & Exp (est) \\
\hline \multirow[t]{4}{*}{ DAY1 } & Intercept & & 1 & -2.50 & 0.97 & 6.72 & 0 & 0.082 \\
\hline & STATE & $\mathrm{SC}$ & 1 & 1.24 & 0.77 & 2.56 & 0.11 & 3.445 \\
\hline & STATE & FL & 1 & 0.05 & 0.93 & 0.00 & 0.96 & 1.053 \\
\hline & NAUTOHH & & 1 & -0.64 & 0.34 & 3.57 & 0.06 & 0.525 \\
\hline \multirow[t]{3}{*}{ DAY2 } & Intercept & & 1 & -2.25 & 0.35 & 41.03 & 0 & 0.106 \\
\hline & STATE* & $\mathrm{SC}$ & 1 & 1.96 & 0.38 & 26.35 & 0 & 7.107 \\
\hline & STATE* & FL & 1 & 1.54 & 0.40 & 14.50 & 0 & 4.659 \\
\hline \multirow[t]{3}{*}{ DAY3 } & Intercept & & 1 & 0.81 & 0.22 & 13.06 & 0 & 2.241 \\
\hline & STATE* & $\mathrm{SC}$ & 1 & -1.58 & 0.28 & 32.75 & 0 & 0.206 \\
\hline & STATE & FL & 1 & -0.41 & 0.30 & 1.92 & 0.17 & 0.664 \\
\hline \multirow[t]{5}{*}{ DAY4 } & Intercept & & 1 & -1.75 & 0.19 & 84.67 & 0 & 0.173 \\
\hline & STATE & $\mathrm{SC}$ & 1 & -0.33 & 0.35 & 0.92 & 0.34 & 0.718 \\
\hline & STATE* & FL & 1 & -1.83 & 0.54 & 11.62 & 0 & 0.161 \\
\hline & PREEXP* & no & 1 & -0.91 & 0.37 & 6.10 & 0.01 & 0.404 \\
\hline & EVACORDER & no & 1 & 0.72 & 0.41 & 3.14 & 0.08 & 2.052 \\
\hline
\end{tabular}

time or day of the evacuation order/announcement, controlling for all other variables. Respondent comments buttress these results-a few comments from Georgia residents were positive with regard to the evacuation experience, but many mentioned difficulties with the evacuation order(s) being issued too late to evacuate (Table 11). In other words, such comments illustrate the triggering nature of an evacuation order, and imply that some were waiting for an authoritative order, and others would have evacuated if the order came sooner.

\section{Conclusions}

This research set out to assess spatial and temporal differences in evacuation behaviors during Hurricane Matthew, taking into account selected household-level variables that could explain such differences in decisions to evacuate and time of departure. Through a survey of coastal residents, descriptive statistics, regression results, and respondent comments we show that there are many small differences in evacuation behaviors and drivers, but there were significant differences in the timing between South Carolina and Georgia, and between Florida and Georgia residents in general. Prior studies have indicated that official evacuation orders significantly and consistently affect whether households evacuate, but as this study thoroughly demonstrates, official evacuation orders also affect the timing of household evacuation. We benefited from the forecast track of the hurricane, which elicited a large and varied response from authorities and residents in three states as the storm moved north. Further, while our statistical results add to the plethora of research on the correlates of evacuation behaviors, the open-response comments from respondents provide initial insight into how or why the nature of the official orders can change the probabilities of evacuation.

In this sample, overall, the residents who evacuated during Hurricane Matthew lacked prior hurricane evacuation experience, received an evacuation order, solicited more information and communicated more with others regarding the order. Not only do our empirical results confirm past research on the significance of evacuation orders from public officials on the evacuation behavior of residents, they highlight that official recommendations may initially be the more influential driver for taking the first steps to make the decision to leave. Moreover, the state variable, a proxy for time of evacuation order, was the only significant variable for each of the three main days of evacuation. The relative differences between the states (e.g., odds ratios) generally matches the times/days of the official recommendations.

The coastline was contained in the cone of uncertainty from National Hurricane Center advisories 22-43 based on the strength of the storm and its path. Many prior studies on departure time have found storm-specific characteristics to be significant in their effects on departure time. We did not include such variables. However, we can infer that the announcement and implementation of mandatory evacuation orders was the major factor influencing state differences and the timing of departures in this sample, rather than simply the proximity to the storm or physical dynamic hurricane properties. Our results support many of the conclusions drawn by Fu et al. (2007) regarding the influence of evacuation order timing on the distribution of evacuees over multiple days. Based on Matthew's forecast path and wind speeds, if proximity, time to landfall, projected storm surge, or strength were as influential as evacuation orders, we would have seen 
TABLE 11. Selected quotations from Georgia respondents reflecting on the timing of the evacuation order.

"Georgia waited too long to issue the evacuation."

"It appeared that the state was the only one considering all surrounding states that did not know what to do and when (...)."

"I thought the governor should have been on TV earlier giving GA residents information. Most of our information was from the FL governor. We live close to JAX so we just followed his instructions."

"The EMA did a poor job at keeping the public informed. The EMA of Camden County didn't issue an evacuation order until late Thursday afternoon."

"It appeared to me and some neighbors that Gov Deal was forced to "up his game" due to the excellent response of Gov Haley in SC. He appeared uninterested until the storm was closing-in on the GA coast."

"Most of the information available was from South Carolina. We had little information available from Georgia (...) This was not just my opinion, it was the opinion of many. We called each other by phone (...) to compare information. Most had little. This was one of the worst evacuations that I have experienced, and because of lack of information, and timely, evacuation notice."

"Not everyone has Facebook so other information output methods would be helpful."

"Make the mandatory evacuation sooner and make employees not demand that employees return to work the day after the hurricane."

"SC was so good, and the Georgia state government was way behind the 8-ball."

"The state office waited [too] long to call the evac (...) Re entry was handled poorly, local authorities did not communicate with each other."

"I felt the state should have gotten involved a little quicker than what they did, knowing that the hurricane was heading in our direction."

"We should follow SC lead next time. They handled it more effectively than GA."

"We depended on a local radio group that had non stop coverage during the storm and aftermath (...) The evacuation notices were not clear and seemed to come very late."

evacuations happening as late as possible in terms of time to landfall (e.g., Sarwar et al. 2016), and generally in order from Florida, then Georgia, then South Carolina. We did not observe that spatial pattern. Whether the orders resulted directly in a household's evacuation response or resulted in a household researching the storm-specific variables that then convinced them to leave, or they resulted in a household discussing possible options with friends or neighbors, clearly the influence of the authoritative recommendation was the motivator for many residents to take protective action. Such findings clearly emphasize the significance of a timely evacuation order.

The aim of this paper was to contribute an additional dimension to the wealth of hurricane evacuation literature through an analysis of the timing of evacuation departures. The limitations discovered in this study-decreasing survey response rates over time, missing responses, or time and monetary constraints of conducting survey research-present opportunities for more methodological improvements and should push us to consider other complementary sources of data for hurricane evacuation research. Other novel methods of assessing evacuation responses, while critical in timeliness of results, may not address the question of why an individual or household did or did not evacuate, or how one evacuation can affect a future evacuation (e.g., Martín et al. 2017). Yet, with more data and complete data, possibly aggregated from multiple sources (e.g., obtaining from a survey a higher response rate with fewer skipped questions, combined with tracking and transportation data), better results could come from similar analyses, with a more complete picture of variables that contribute to evacuation behaviors.
Acknowledgments. We thank the surveyed residents of Florida, Georgia, and South Carolina for taking the time to respond to our questionnaire. This study would not be possible without them. We also thank the three anonymous reviewers for their helpful comments.

\section{REFERENCES}

Arlikatti, S., M. K. Lindell, C. S. Prater, and Y. Zhang, 2006: Risk area accuracy and hurricane evacuation expectations of coastal residents. Environ. Behav., 38, 226-247, https://doi.org/10.1177/ 0013916505277603.

Baker, E. J., 1991: Hurricane evacuation behavior. Int. J. Mass Emerg. Disasters, 9, 287-310.

Bowser, G. C., and S. L. Cutter, 2015: Stay or go? Examining decision making and behavior in hurricane evacuations. Environment, 57, 28-41, https://doi.org/10.1080/00139157. 2015.1089145.

Broad, K., A. Leiserowitz, J. Weinkle, and M. Steketee, 2007: Misinterpretations of the "cone of uncertainty" in Florida during the 2004 hurricane season. Bull. Amer. Meteor. Soc., 88, 651-668, https://doi.org/10.1175/BAMS-88-5-651.

Collins, J., R. Ersing, and A. Polen, 2017: Evacuation decisionmaking during Hurricane Matthew: An assessment of the effects of social connections. Wea. Climate Soc., 9, 769-776, https://doi.org/10.1175/WCAS-D-17-0047.1.

,,,,-- M. Saunders, and J. Senkbeil, 2018: The effects of social connections on evacuation decision making during Hurricane Irma. Wea. Climate Soc., 10, 459-469, https://doi.org/ 10.1175/WCAS-D-17-0119.1.

Cull, W. L., K. G. O'Connor, S. Sharp, and S.-f. S. Tang, 2005: Response rates and response bias for 50 surveys of pediatricians. Health Serv. Res., 40, 213-226, https://doi.org/10.1111/ j.1475-6773.2005.00350.x.

Dash, N., and B. H. Morrow, 2000: Return delays and evacuation order compliance: The case of Hurricane Georges and the Florida Keys. Global Environ. Change, 2, 119-128, https:// doi.org/10.1016/S1464-2867(01)00008-0. 
Demuth, J. L., R. E. Morss, J. K. Lazo, and C. Trumbo, 2016: The effects of past hurricane experiences on evacuation intentions through risk perception and efficacy beliefs: A mediation analysis. Wea. Climate Soc., 8, 327-344, https://doi.org/10.1175/ WCAS-D-15-0074.1.

Dixit, V., C. Wilmot, and B. Wolshon, 2012: Modeling risk attitudes in evacuation departure choices. Transp. Res. Rec., 2312, 159163, https://doi.org/10.3141/2312-17.

Dow, K., and S. L. Cutter, 1998: Crying wolf: Repeat responses to hurricane evacuation orders. Coastal Manage., 26, 237-252, https://doi.org/10.1080/08920759809362356.

— Floyd and South Carolina. Nat. Hazards Rev., 3, 12-18, https:// doi.org/10.1061/(ASCE)1527-6988(2002)3:1(12).

Edmonds, A. S., and S. L. Cutter, 2008: Planning for pet evacuations during disasters. J. Homel. Secur. Emerg. Manage., 5, 1547-7355, https://doi.org/10.2202/1547-7355.1445.

Eiser, J. R., A. Bostrom, I. Burton, D. M. Johnston, J. McClure, D. Paton, J. van der Pligt, and M. P. White, 2012: Risk interpretation and action: A conceptual framework for responses to natural hazards. Int. J. Disaster Risk Reduct., 1, 5-16, https:// doi.org/10.1016/j.ijdrr.2012.05.002.

Fan, W., and Z. Yan, 2010: Factors affecting response rates of the web survey: A systematic review. Comput. Hum. Behav., 26, 132-139, https://doi.org/10.1016/j.chb.2009.10.015.

Fu, H., C. G. Wilmot, H. Zhang, and E. J. Baker, 2007: Modeling the hurricane evacuation response curve. Transp. Res. Rec., 2022, 94-102, https://doi.org/10.3141/2022-11.

Guo, Y., J. A. Kopec, J. Cibere, L. C. Li, and C. H. Goldsmith, 2016: Population survey features and response rates: A randomized experiment. Amer. J. Public Health, 106, 1422-1426, https://doi.org/10.2105/AJPH.2016.303198.

Hasan, S., R. Mesa-Arango, and S. Ukkusuri, 2013: A randomparameter hazard-based model to understand household evacuation timing behavior. Transp. Res., 27C, 108-116, https:// doi.org/10.1016/j.trc.2011.06.005.

Huang, S. K., M. K. Lindell, and C. S. Prater, 2016: Who leaves and who stays? A review and statistical meta-analysis of hurricane evacuation studies. Environ. Behav., 48, 991-1029, https:// doi.org/10.1177/0013916515578485.

Johnson, T. P., and J. S. Wislar, 2012: Response rates and nonresponse errors in surveys. J. Amer. Med. Assoc., 307, 18051806, https://doi.org/10.1001/jama.2012.3532.

Kang, H., 2013: The prevention and handling of the missing data. Korean J. Anesthesiol., 64, 402, https://doi.org/10.4097/ kjae.2013.64.5.402.

Koshute, P., 2013: Evaluation of existing models for prediction of hurricane evacuation response curves. Nat. Hazards Rev., 14, 175181, https://doi.org/10.1061/(ASCE)NH.1527-6996.0000108.

Leece, P., M. Bhandari, S. Sprague, M. F. Swiontkowski, E. H. Schemitsch, P. Tornetta, P. J. Devereaux, and G. H. Guyatt, 2004: Internet versus mailed questionnaires: A controlled comparison (2). J. Med. Internet Res., 6, e39, https://doi.org/ 10.2196/jmir.6.4.e39.

Lindell, M. K., and C. S. Prater, 2007: Critical behavioral assumptions in evacuation time estimate analysis for private vehicles: Examples from hurricane research and planning. J. Urban Plann. Dev., 133, 18-29, https://doi.org/10.1061/ (ASCE)0733-9488(2007)133:1(18).

_ - J. C. Lu, and C. S. Prater, 2005: Household decision making and evacuation in response to Hurricane Lili. Nat. Hazards Rev., 6, 171-179, https://doi.org/10.1061/(ASCE) 1527-6988(2005)6:4(171).
_ J. E. Kang, and C. S. Prater, 2011: The logistics of household hurricane evacuation. Nat. Hazards, 58, 1093-1109, https:// doi.org/10.1007/s11069-011-9715-x.

_ - S. Arlikatti, and S. K. Huang, 2019: Immediate behavioral response to the June 17, 2013 flash floods in Uttarakhand, North India. Int. J. Disaster Risk Reduct., 34, 129-146, https:// doi.org/10.1016/j.ijdrr.2018.11.011.

Little, R. J. A., and D. B. Rubin, 2002: Statistical Analysis with Missing Data. John Wiley and Sons, 408 pp.

Martín, Y., Z. Li, and S. L. Cutter, 2017: Leveraging Twitter to gauge evacuation compliance: Spatiotemporal analysis of Hurricane Matthew. PLOS ONE, 12, e0181701, https://doi.org/ 10.1371/journal.pone.0181701.

Mileti, D. S., and L. Peek, 2000: The social psychology of public response to warnings of a nuclear power plant accident. J. Hazard. Mater., 75, 181-194, https://doi.org/10.1016/S03043894(00)00179-5.

_- , and J. H. Sorensen, 2019: A guide to public alerts and warnings for dam and levee emergencies. U.S. Army Corps of Engineers Pamphlet EP 1110-2-17, 30 pp., https:/ www.publications.usace.army.mil/Portals/76/Users/182/86/2486/ EP\%201110-2-17.pdf?ver=2019-06-20-152050-550.

National Weather Service, 2006: Hurricane Charley, August 9-15, 2004, NOAA/National Weather Service Service Assessment, 29 pp., https://www.weather.gov/media/publications/assessments/ Charley06.pdf.

Pasch, R. J., D. P. Brown, and E. S. Blake, 2004: Hurricane Charley (9-14 August 2004). National Hurrican Center Tropical Cyclone Rep., 23 pp., https://www.nhc.noaa.gov/data/tcr/ AL032004_Charley.pdf.

Pel, A. J., S. P. Hoogendoorn, and M. C. J. Bliemer, 2010: Evacuation modeling including traveler information and compliance behavior. Procedia Eng., 3, 101-111, https://doi.org/ 10.1016/J.PROENG.2010.07.011.

Sarwar, M. T., P. C. Anastasopoulos, S. V. Ukkusuri, P. Murray-Tuite, and F. L. Mannering, 2016: A statistical analysis of the dynamics of household hurricane-evacuation decisions. Transportation, 45, 51-70, https://doi.org/10.1007/s11116-016-9722-6.

Sbayti, H., and H. Mahmassani, 2006: Optimal scheduling of evacuation operations. Transp. Res. Rec., 1964, 238-246, https://doi.org/10.1177/0361198106196400126.

Smith, S. K., and C. McCarty, 2009: Fleeing the storm(s): An examination of evacuation behavior during Florida's 2004 hurricane season. Demography, 46, 127-145, https://doi.org/ 10.1353/dem.0.0048

Stein, R. M., L. Dueñas-Osorio, and D. Subramanian, 2010: Who evacuates when hurricanes approach? The role of risk, information, and location. Soc. Sci. Q., 91, 816-834, https:// doi.org/10.1111/j.1540-6237.2010.00721.x.

Stewart, S. R., 2016: Hurricane Matthew (AL142016). National Hurricanes Center Tropical Cyclone Rep., 96 pp., https:// www.nhc.noaa.gov/data/tcr/AL142016_Matthew.pdf.

Whitehead, J. C., 2003: One million dollars per mile? The opportunity costs of hurricane evacuation. Ocean Coastal Manage., 46, 1069-1083, https://doi.org/10.1016/j.ocecoaman.2003.11.001.

_ , B. Edwards, M. Van Willigen, J. R. Maiolo, K. Wilson, and K. T. Smith, 2000: Heading for higher ground: Factors affecting real and hypothetical hurricane evacuation behavior. Environ. Hazards, 2 , 133-142, https://doi.org/10.1016/S1464-2867(01)00013-4.

Wong-Parodi, G., and I. Feygina, 2018: Factors influencing (mal) adaptive responses to natural disasters: The case of Hurricane Matthew. Wea. Climate Soc., 10, 747-768, https://doi.org/ 10.1175/WCAS-D-17-0138.1. 